\title{
PLATYPNEA AND ORTHODEOXIA: SHUNTING ASSOCIATED WITH AN AORTIC ANEURYSM
}

\author{
Katherine A. Laybourn, MD, ${ }^{\text {a }}$ Edward T. Martin, MD, ${ }^{\mathrm{b}}$ Randolph A. S. Cooper, MD, ${ }^{\mathrm{b}}$ and William L. Holman, MD, ${ }^{\mathrm{a}}$ \\ Birmingham, Ala.
}

Dyspnea and deoxygenation associated with sitting or standing from recumbency, referred to as platypnea and orthodeoxia, is a rare but striking clinical syndrome. We present a case of platypnea and orthodeoxia syndrome that was associated with a patent foramen ovale and an aneurysm of the ascending aorta.

Clinical summary. A 54-year-old man had been in good health until 6 months before presentation, when he noticed increasingly severe shortness of breath on exertion. In addition, he had lower back pain and was admitted to his local hospital, where he was evaluated and treated with antiinflammatory drugs. During this hospital admission, the patient had an episode of severe shortness of breath and was found to have peripheral desaturation to $80 \%$ while breathing room air. Before referral, a transesophageal echocardiogram showed a dilated ascending aorta and a right-to-left shunt at the atrial level. On arrival at this hospital, physical findings included a blood pressure of $120 / 76 \mathrm{~mm} \mathrm{Hg}$, a heart rate of 85 beats/min, a respiratory rate of 24 breaths $/ \mathrm{min}$, and no evidence of orthostatic blood pressure changes. The findings on cardiovascular examination with the patient recumbent were within normal limits. An electrocardiogram showed normal sinus rhythm with no abnormal findings. Pulmonary function studies included a ratio of forced expiratory volume in 1 second to forced vital capacity of $80 \%$. The patient's arterial oxygen tension in the sitting position while breathing $100 \%$ oxygen from a closed face mask was $58 \mathrm{~mm} \mathrm{Hg}$ as compared with $113 \mathrm{~mm} \mathrm{Hg}$ in the supine position. Transesophageal echocardiographic contrast studies demonstrated a dilated ascending aorta and a right-to-left shunt at the atrial level that increased as the patient sat up. Cardiac catheterization showed normal hemodynamics including a cardiac index of $2.07 \mathrm{~L} / \mathrm{min}$ per square meter, a mean right atrial pressure of $2 \mathrm{~mm} \mathrm{Hg}$, a pulmonary artery wedge pressure of $7 \mathrm{~mm} \mathrm{Hg}$, and a pulmonary artery pressure of $15 / 5 \mathrm{~mm} \mathrm{Hg}$ with a mean of $8 \mathrm{~mm} \mathrm{Hg}$. The presence of a patent foramen ovale was confirmed at catheterization. Because of the patient's disabling dyspnea and $6 \mathrm{~cm}$ ascending aortic aneurysm,

From the Departments of Surgery ${ }^{\mathrm{a}}$ and Medicine, ${ }^{\mathrm{b}}$ Birmingham Veterans Administration Medical Center and University of Alabama at Birmingham, Birmingham, Ala.

This work was performed during Dr. Holman's tenure as an Established Investigator for the American Heart Association.

Received for publication Nov. 15, 1996; accepted for publication Nov. 27, 1996.

Address for reprints: William L. Holman, MD, Associate Professor of Surgery, Division of Cardiothoracic Surgery, University Station, Birmingham, AL 35294-0007.

J Thorac Cardiovasc Surg 1997;113:955-6

$12 / 54 / 79609$ surgical intervention was recommended. At the time of the operation, the patent foramen ovale was closed and the ascending aorta was replaced with a Dacron graft. Postoperatively, the patient's condition improved and his dyspnea resolved.

Comment. This report documents platypnea and orthodeoxia as a result of right-to-left shunting across a patent foramen ovale in association with an ascending aortic aneurysm. Platypnea and orthodeoxia is a rare disorder of postural dyspnea and deoxygenation that was first described by Burchell, Helmolz, and Wood ${ }^{1}$ in 1949. In 1984, Seward and associates ${ }^{2}$ published a report of seven cases that is useful as a guide for evaluating patients with this syndrome. Three general groups of disorders that have been associated with the platypnea and orthodeoxia syndrome include (1) pulmonary disorders (e.g., pulmonary arteriovenous shunts, chronic obstructive pulmonary disease, and pneumonectomy), (2) intracardiac right-to-left shunts (e.g., patent foramen ovale), and (3) extrathoracic disorders (e.g., hepatic disease and ascites). ${ }^{2-5}$ An increase in shunting across a patent foramen ovale that is associated with sitting or standing from a recumbent position can be caused by a deformity of the atrial septum that directs venous flow directly at the foramen ovale. Disorders that distort the atrial septum, like the surgical removal of a lung, are thought to cause platypnea and orthodeoxia by this mechanism.

The patient described in this report is unique because he did not have any of the pulmonary or extracardiac diseases that have previously been associated with the platypnea and orthodeoxia syndrome. Instead, enlargement of the ascending aorta rotated the heart in a counterclockwise direction, thereby distorting the position of the atrial septum relative to caval inflow. We believe that this shift in position directed the right atrial venous inflow through a patent foramen and that the shunt flow was exacerbated when the patient was in an upright position. The findings on transesophageal echocardiography and the resolution of this patient's symptoms after surgical correction suggest that this interpretation is correct.

Addendum. After this case, we encountered another patient with platypnea orthodeoxia syndrome associated with an aortic aneurysm and a patent foramen ovale. This 86-year-old woman was bedridden because sitting or standing would result in incapacitating symptoms of dyspnea and fatigue. Her arterial hemoglobin oxygen saturation was over $90 \%$ while recumbent, but on sitting her oxygen saturation fell to $80 \%$. Her oxygen saturation was not increased despite breathing supplemental oxygen. Magnetic resonance imaging and contrast echocardiography showed a $7.6 \mathrm{~cm}$ ascending aortic aneurysm arising above the sinotubular junction and a patent foramen ovale. The contrast echocardiogram further demonstrated 
a right-to-left shunt when the patient was in the sitting position. Resection and grafting of the ascending aortic aneurysm with closure of the patent foramen ovale successfully abolished the patient's symptoms.

\section{REFERENCES}

1. Burchell HB, Helmolz HF Jr, Wood EH. Reflex orthostatic dyspnea associated with pulmonary hypotension (abstract). Am J Physiol 1949;159:563-4.

2. Seward JB, Hayes DL, Smith HC, et al. Platypnea-orthode- oxia: clinical profile, diagnostic workup, management, and report of seven cases. Mayo Clin Proc 1994;59:221-31.

3. Sorrentino M, Resnekov L. Patent foramen ovale associated with platypnea and orthodeoxia. Chest 1991;100:1157-8.

4. Timmermans C, Frans E, Herregods C, Decramer M, Daenen W, DeGeest H. Platypnea-orthodeoxia syndrome: a report of two cases. Acta Cardiol 1993;6:583-90.

5. Dear WE, Chen P, Barasch E, Anderson HV, Varughese AT, Macris MP. Sixty-eight year old woman with intermittent hypoxemia. Circulation 1995;91:2284-9. 